\title{
3.2.5 THE PROUST RADAR: FIRST RESULTS
}

F. Bertin, A. Cremieu, M. Glass, M. Mas sebeuf, and M. Petitdidier

\section{CNET/CRPE}

4 Av. de Neptune

94107 . St Maur des Fosses, France

Two campaigns took place in 1984 with the PROUST Radar operating in a bistatic mode, the transmitting antenna pointing at the vertical and the receiving one, $1^{\circ}$ of $f$ the vertical axis. The antenn bean intersection covers an altitude range between 3 and $9 \mathrm{~km}$. A complete description of the radar characteristics can be found in BERTIN et 81 . (1986). The first of these campaigns are analysed here.

\section{LEE WAVES OBSERVATION DURING AN "AUTAN WIND" SITUATION.}

The "Autan" wind is a strong southeasterly wind observed in the southwest of France, generated by a typical synoptic situation: high pressure over Scandinavia associated with $10 \mathrm{w}$ pressure over Spain. Radiosonde measurenents yield a horizontal wind contribution of at most $0.2 \mathrm{~m} / \mathrm{s}$ along the radar lineof-sight. The dashed 1ine in Figure $1 \mathrm{~b}$ gives the observed vertical wind profile, and the vertical line, the estimated horizontal wind contribution. The observed wind can be regarded as mainly due to the vertical component. Over the whole range of observed altitude, a downward wind is detected with an amplitude that decreases from $1.2 \mathrm{~m} / \mathrm{s}$ (at $3 \mathrm{~km}$ ) to $0.25 \mathrm{~m} / \mathrm{s}$ (at $7.2 \mathrm{~km}$ ). The horizontal bars give the error on the vertical wind, inferred from the Doppler shift estimation. This profile shape might be interpreted as due to the interaction between "Autan" wind and "Massif Central " topography. In order to test this assumption, the 1 ee wave model of QUENEY (1948) is used (Figure 1a). This model gives a downward vertical wind above St Santin up to $7 \mathrm{~km}$. For comparison, this theoretical wind profile is al so plotted in Figure 1b. A good agreement is found between observation and theory, the systematic difference between the two profiles being probably due to the horizontal wind contribution.

\section{OBSERVATION OF WAVE - TURBULENCE INTERACTION IN A STORMY WARM FRONT}

On June 6 th, 1984, a stormy warm front was crossing over St Santin. The echo power profiles associated with this front show an intense turbulence observed both on the refractive index (signa1-to-noise ratio) and on the vertical wind fluctuations (spectral broadening). Figure 2 shows the spatiotemporal evolution of the radar echo intensity and Doppler shift in the al ti tude range $3-10 \mathrm{~km}$. In each gate, the echo power ( $\mathrm{S} / \mathrm{N}$ ratio expressed in $\mathrm{dB}$ ) is scaled according to a dashed code. The Doppler shift is scaled in $\mathrm{m} / \mathrm{s}$ on the vertical axis, while the 1 ocal time is scaled in hours on the horizontal axis. The contribution of the horizontal wind is, in this experiment, never greater than $0.1 \mathrm{~m} / \mathrm{s}$. The mean value of the Doppler shift gives evidence of a g1 obal upward wind of about $1 \mathrm{~m} / \mathrm{s}$ during the front crossing. Associated with this global upward movement, a very active turbulence gives rise to the observed radar echoes.

2.1 Estimation of the energy dissipation rate. For the strongest echoes (occurring in gates $n^{\circ} 6$ and 7 ), a spectral broadening of about $0.5 \mathrm{~m} / \mathrm{s}$ is observed. It is noteworthy that the spectral broadening due to the deformations introduced by the antenna beam gecmetry (and detailed in SPIZZICHINO, 1975) is estimated to be never greater than $0.1 \mathrm{~m} / \mathrm{s}$. In these conditions, the observed spectral widths give an estimation of the rms value of the turbulent wind fluctuations $w$ ' al ong the vertical. The energy dissipation rate $\varepsilon$ can be easily inferred from $w$ ' by using the following expression 


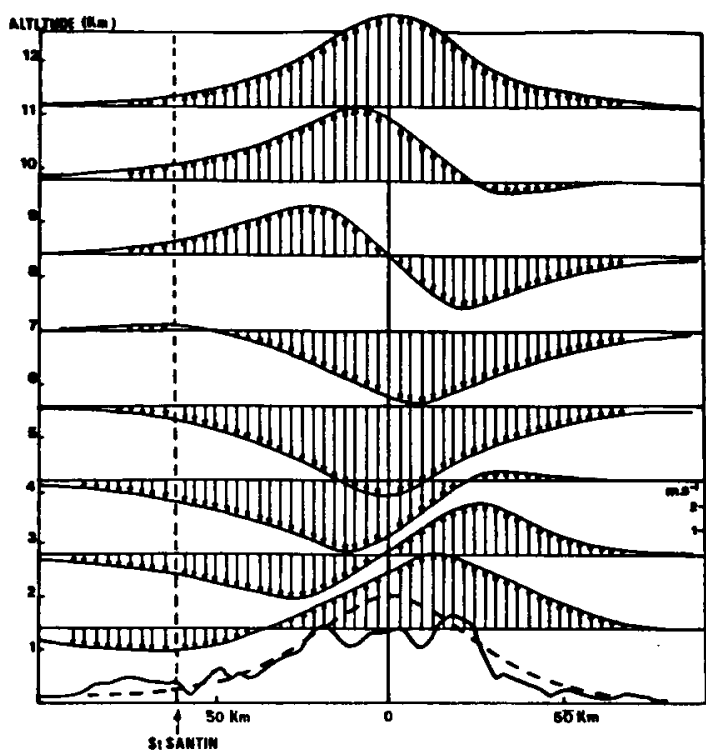

Figure 1a. Vertical velocity field and streanlines over the "Massif Central". modelised by a symetrical shape.

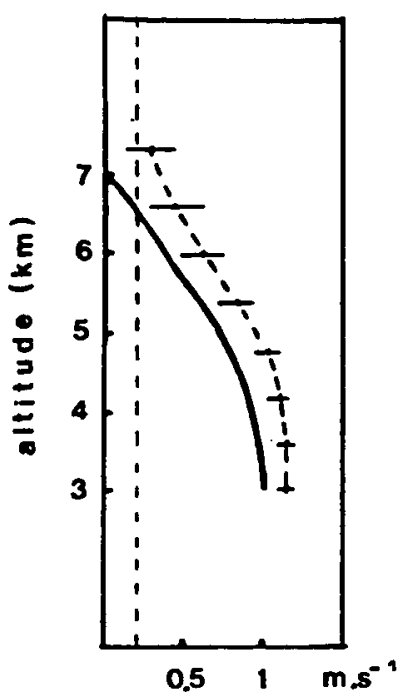

Figure 1b. Vertical wind profile (observed and theoretica1).

proposed by WEINSTOCK (1981).

$$
\varepsilon=0.4 \overline{\mathrm{W}^{2}} \omega_{B}
$$

where $\omega_{B}$ is the Brunt-Vaisala frequency.

Figure 3 shows the Brunt-Vaisala period (BVP) profile, obtained from radiosonde data. Finally, relation (1) yields an energy dissipation rate value in the range

$$
1.10^{-3}<\varepsilon<2.10^{-3} \mathrm{~m}^{2} \mathrm{~s}^{-3}
$$

for the strongest echoes observed in gate $n^{\circ} 7$. This is a typical value for a very active turbulence (LILLY et al., 1974).

2.2 Waves and turbulence. Besides the global upward movement of the air al ong the front, oscillations are observed in the vertical wind intensity, period and amplitude of which vary vers us altitude. In gates $n^{\circ} 8$ to 10 . oscillations with a range period of 8-9 minutes are clearly observed, while a 3minute period appears in gates $n^{\circ} 6$ and 7 just after the strong intensification of the turbulent activity mentioned above. Comparison between these periods and the BVP profile plotted in Figure 3 exhibits a striking agreement. This observation is consistent with theoretical studies on gravity waves generated by turbulence in stratified fluids. WEINSTOCK $(1978,1981)$ has shown that, in a stratified atmosphere, the time evolution of the vertical velocity spectrum implies the emission of gravity waves, generated by the vertical motion of the air particles, with a frequency $\omega_{K}$ given by:

$$
\omega_{K}=\omega_{B} \frac{K_{H}}{K}
$$




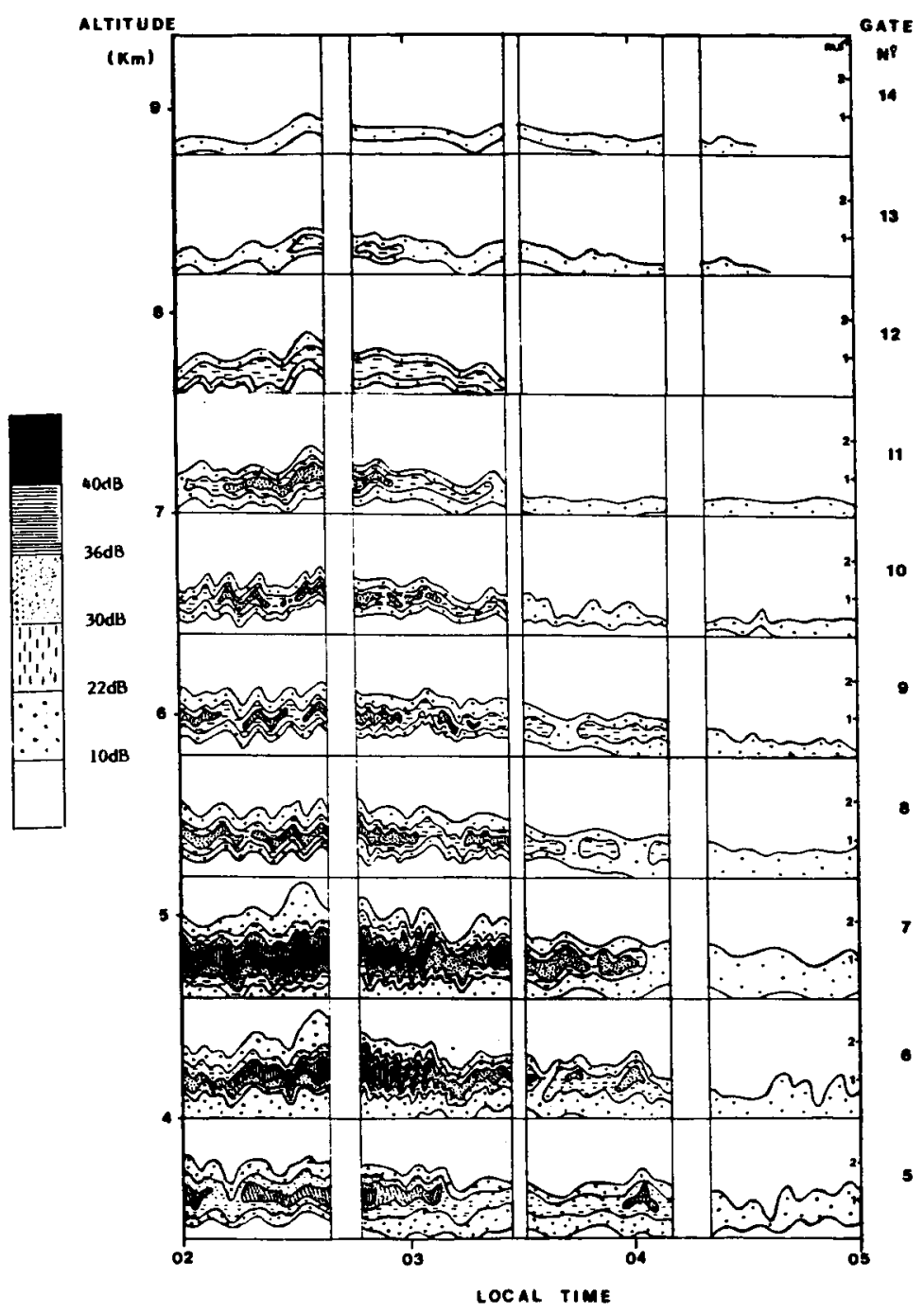

Figure 2. Spatio-temporal evolution of the radar echo power on June 6 , 1984.

where $\mathrm{K}$ is the wave number and $\mathrm{K}_{\mathrm{H}}$ its horizontal component. The good correlation between $\mathrm{BV}$ and observed frequency seems to indicate that the wave propagation is mainly horizontal. These propagation characteristics are also found by METAIS (1984) with a numerical model.

\section{CONCLUSION}

The first results analysed above show the capability of the PROUST Radar to measure the turbulent parameters and study the turbulence-wave interaction. In its present configuration (bistatic mode and $600 \mathrm{~m}$ vertical resolution). it has been necessary to make some assumptions that are known not to be truly fulfilled: homogeneous turbulence and constant vertical wind intensity over a 600-m thickness. It is clear that a more detailed study of the interaction 


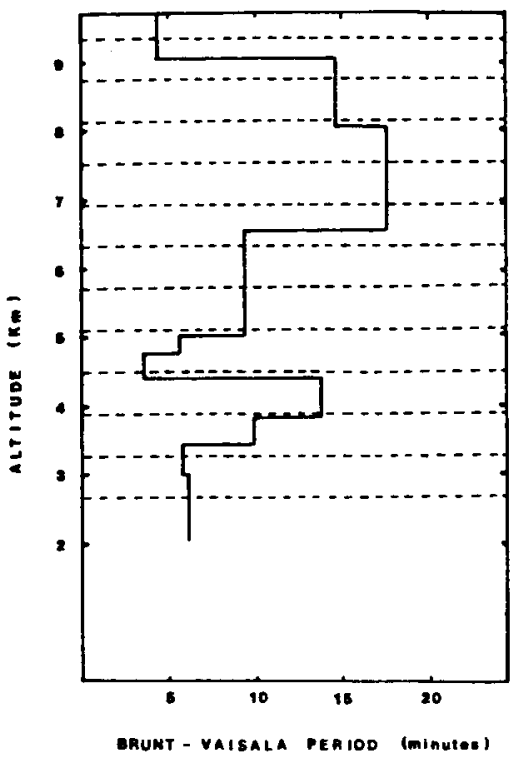

Figure 3.

between wave and turbulence will be possible with the next version of PROUST Radar (30-m al titude resolution and monostatic mode) that will soon be achieved.

\section{REFEREN CES}

Bertin, F., M. Glass, R. Ney, and M. Petitdidier (1986). The PROUST Radar, this volume.

Lilly, D. K., D. E. Waco, and S. I. Adel fang (1974), Stratospheric mixing estimated from high-al titude turbulence measurements, J. Appl. Meteorol., 13. 488-493.

Metais, 0. (1985). Direct numerical simulation of stratified turbulence, 5 th Symp. on Turb. Shear Flows.

Queney, P. (1975). The problem of airflow over a mountains: a summary of theoretical studies, Bull. Am. Meteoro1. Soc., 29, 16-26.

Spizzichino, A. (1975), Spectral broadening of acoustic and radio waves scattered by atmospheric turbulence in the case of radar and sodar experiments, Ann. Geophys.. 31, 433-445.

Weinstock, J. (1978), On the theory of turbulence in the buoyancy subrange of stratified flows, J. Atmos. Sci. 35, 635-659.

Weinstock, J. (1981). Vertical turbulence diffusivity for weak or strong stable stratification, J. Geophys. Res.. 86, 9925-9928. 